\title{
Suhtalar and Extra Articular Synovial Chondromatasis
}

\author{
S. Bahari, J. McKenna \\ From the Foot and Ankle Unit, \\ Department of Trauma and Orthopaedic Surgery, \\ St James' Hospital, Dublin 8
}

\begin{abstract}
:
Synovial chondromatosis is an uncommon condition affecting large joints such as hip, knee, shoulder and elbow. Diagnosis can be achieved by history, examination and radiographic findings. Histological diagnosis is definitive. A 53 year old female patient presented with 2 months history of ankle injury and was treated as ankle sprain. A diagnosis of monoarticular synovial chondromatosis affecting the subtalar joint with extra articular involvement was made and treated with excision of lesion with satisfactory outcome at one-year review. We found 4 cases of subtalar synovial chondromatosis in the English literature but no history of trauma documented their presenting compliant. The injury had prompted the investigation, treatment and may contribute to the satisfactory outcome as the condition was treated at an earlier stage.
\end{abstract}

Key words: Synovial chondromatosis, Subtalar joint, Trauma

\section{Introduction}

Synonial chondromatosis is an uncommon condition characterised by synovial metaplasia and hyperplasia affecting large joints such as hip, knee, shoulder and elbow. Smaller joints are rarely affected [1,2]. Diagnosis can be achieved by history, examination and radiographic findings. Histological diagnosis is definitive [2]. History of trauma is uncommon. We report a case of monoarticular synovial chondromatosis affecting the subtalar joint with extra articular involvement treated with excision of lesion with satisfactory outcome at oneyear review.

\section{Case Report}

A 53 years old female presented to our foot and ankle clinic with a history of ankle sprain of her left foot and ankle. She sustained the injury 2 months prior. She attended her general practitioner and was treated for ankle sprain. She had ankle brace and underwent two sessions of physiotherapy. She was complaining of pain and swelling on the lateral aspect of the foot and ankle. Pain in the ankle was relieved by rest and non-steroidal anti-inflammatory drugs. She had previous history of sprain of the left ankle. She has no history of locking or giving way of the ankle.

On examination, she was able to bear full weight with no evidence of skin discolouration and calf muscle wasting. Her foot was plantigrade with normal alignment. She had a non tender, focally palpable swelling over 
the lateral aspect of the ankle and foot extending from the distal fibula to the lateral aspect of the foot. The lesion was firm, non transilluminating, not mobile, not moving with ankle or foot movement and non-adherent to the skin. Neurovascular examination was normal. She had limitation of ankle dorsiflexion and subtalar movement compared to the uninjured side. Her midfoot movement was satisfactory. Resisted movement of ankle was satisfactory. There was no evidence of ankle instability on anterior draw or clinical evidence of infection. The inflammatory markers were negative.

Plain radiograph of the foot and ankle revealed a $2.7 \mathrm{~cm}$ erosive lesion affecting the medial aspect of distal fibula and lateral aspect of distal tibia [Figure 1]. Magnetic resonance imaging (MRI) scan was performed to further evaluate the lesion. Lesion with increased signal intensity on T2 weighted image was identified in the subtalar joint and extending to the distal tibia - fibula joint on the lateral aspect of the foot [Figure 2]. The lesion was not arising from the bone. The lesion was well demarcated with narrow zone of transition suggestive of benign pathology.

Open excision biopsy was performed through an incision centred over the sinus tarsi. A white firm, papillary like tissue was found arising from subtalar joint and extending proximally toward the distal tibia - fibula joint [Figure 3]. The ankle joint however was not involved when examined arthroscopically. Histological result confirmed the diagnosis of synovial chondromatosis. At one year follow up, patient was back to return to normal activity without any sign of recurrence.

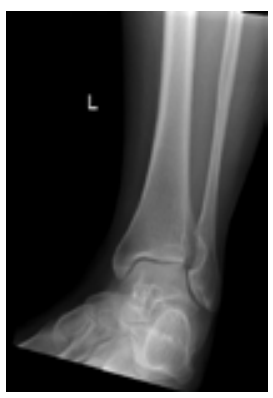

Fig.1: Anteroposterior view of the left ankle erosion of the distal fibula

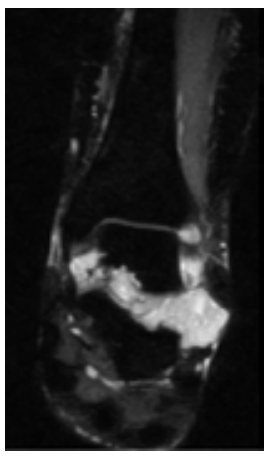

Fig.2: Magnetic resonance imaging (MRI) of the left ankle. T2 image showing high signal intensity in the subtalar joint extending to the distal fibula 


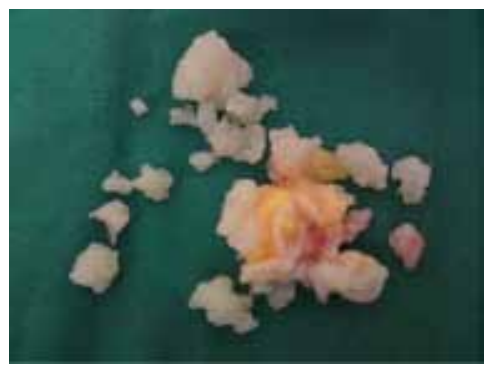

Fig.3: White firm. nodule like soft tissue excised from subtalar joint and distal fibula

\section{Discussion}

Patients with synovial chondromatosis may present with chronic symptoms of pain and swelling of the affected joint. They may also describe sensation of locking and stiffness [1,2]. Previous history of trauma is uncommon [2], which suggest the condition is primary hypertrophic or metaplastic process rather than secondary to trauma. Risk of malignant transformation has been reported but still considered rare [3]. History of trauma is uncommon which happen in our case that differs from other cases reported before [Table 1] [4-6].

Synovial chondromatosis affects male 2 to 4 times more than female and commonly presented in the 3 rd to 4 th decade of life $[1,2]$. This condition rarely presented in children [7]. No genetic risk factor was identified but there is a case reported in sibling [6].

Synovial chondromatosis can be classified into primary and secondary [1]. Secondary synovial chondromatosis is thought due to intra articular joint degeneration with loose body formation. The loose body fragments may cause synovitis and subsequently causing synovial metaplasia and hyperplasia. However, the cause for primary synovial chondromatosis is unknown.

The pathophysiology of this disease is characterised by synovial metaplasia and hyperplasia with hyaline or myxoid cartilage formation [2]. The synovial lining developed nodular proliferation. Nourished by the synovial fluids, these nodules can grow, become calcified or fragmented. These nodules vary in sizes and they can break off as intra articular loose bodies or embedded in the synovium or periarticular soft tissue. The presence of intra

Table 1: Summary of the reports published on subtalar synovial chondromatosis

\begin{tabular}{|llllllll|l|}
\hline Author & $\begin{array}{l}\text { Year } \\
\text { Published }\end{array}$ & Age & Sex & $\begin{array}{l}\text { Mode of } \\
\text { presentation }\end{array}$ & Xray & CT scan & MRI & Treatment \\
\hline Hocking & 2003 & 15 & M & Elective & Yes & Yes & Yes & Excision+Arthrodesis \\
Hocking & 2003 & 15 & M & Elective & Yes & Yes & No & Arthrodesis \\
Van & 2004 & 56 & F & Elective & Yes & No & Yes & Excision \\
Kerimoglu & 2008 & 35 & F & Elective & Yes & No & Yes & Excision \\
Bahari & 2012 & 53 & F & Trauma & Yes & No & Yes & Excision \\
\hline
\end{tabular}


articular loose fragment can cause third body wear thus the disease progression can leads to degenerative joint disease and secondary osteoarthritis. Extra articular nodules can cause pressure effect on adjacent structures thus becoming symptomatic. Bony erosion is recognised as pressure effect from these nodules.

Milgram [2] described 3 distinct phases of the disease process. In phase 1, there is metaplasia of the synovial lining. Synovitis and nodular formation may be present without calcification. In phase 2, nodular synovitis and loose bodies are predominant in the joint. These nodules are still cartilaginous. In phase 3, the synovitis resolved but the nodules are likely to unite and calcified. They may stay as loose bodies or adhered to the synovium.

The disease commonly affects large joint but small joint is a rarity [1,2]. The condition is thought to be monoarticular but there is a case of bilateral joint involvement [8]. Most common joint reported was the knee [9]. A search through the literature limited to English, we found 4 reported cases [4-6] of subtalar involvement with only 2 cases with extra articular involvement in the last 10 years [Table 1].

In diagnosing synovial chondromatosis, plain radiography, ultrasonography, computed tomography and MRI with contrast are useful. Calcified synovial chondromatosis can be recognised with plain radiography. Articular erosion is also diagnostic feature [4]. For non-calcified lesion, other imaging is required. Ultrasound has been reported to be useful in diagnosing synovial chondromatosis [10] but their diagnostic accuracy is operator dependant. CT scan has better resolution and able to detect less calcified lesion [11] but their downside is an increase radiation exposure. Magnetic resonance imaging (MRI) is a more useful diagnostic modality as it non radioactive and more sensitive in detecting synovial chondromatosis at an early stage and estimating the extent of the lesion. Knowledge of MRI features of non-calcified or calcified synovial chondromatosis is important as to distinguish between effusion, haemarthrosis or synovial process as patient may present with history of trauma [12].

Surgical excision of lesion was reported in 3 cases [4-6]. In our case, open surgical excision was performed with satisfactory outcome at one year with no clinical evidence of recurrence or joint arthrosis. Arthrodesis or arthroplasty is an option in joint with significant degenerative changes [13]. In one case, subtalar arthrodesis was performed as secondary procedure [4] due to persistent pain. Primary subtalar arthrodesis has also been performed with satisfactory outcome as his brother has satisfactory outcome from arthrodesis [4]. Malignant transformation was reported with relative risk of $0.5 \%$ progression from primary synovial chondromatosis [14]. Clinically and radiologically, it is difficult to distinguish primary synovial chondromatosis from primary chondrosarcoma [3]. However, this is still considered rare with an argument that it may be a case of misdiagnosis [8].

\section{Conclusion}

Mono-articular synovial chondromatosis with extra articular involvement of the subtalar joint is a rare case. Clinical presentations are often non-specific and long standing. History of trauma was uncommon but may have been the contributing factor in the satisfactory final outcome. There was minimal degenerative changes in the subtalar joint at time of presentation may due to the earlier stage of the disease. The injury had prompted the referral, investigations and treatment, which may have prevent degenerative changes in the subtalar joint in the long term. 


\section{References}

1. Valmassy R, Ferguson H. Synovial osteochondromatosis. A brief review. J Am Podiatr Med Assoc. 1992;82(8):427-431.

2. Milgram JWL. Synovial osteochondromatosis: a histopathological study of thirty cases. J Bone Joint Surg Am. 1977;59:792-801.

3. Sperling BL, Angel S, Stoneham G, Chow V, McFadden A, Chibbar R. Synovial chondromatosis and chondrosarcoma: a diagnostic dilemma. Sarcoma. 2003;7(2):69-73.

4. Hocking R, Negrine J. Primary synovial chondromatosis of the subtalar joint affecting two brothers. Foot Ankle Int.2003;24(1 1):865-867.

5. Van P, Wilusz PM, Ungar DS, Pupp GR. Synovial chondromatosis of the subtalar joint and tenosynovial chondromatosis of the posterior ankle. J Am Podiatr Med Assoc. 2006;96(1):59-62.

6. Kerimoglu S, Aynaci O, Saracoglu M, Cobanoglu U. Synovial chondromatosis of the subtalar joint: a case report and review of the literature. J Am Podiatr Med Assoc. 2008; 98(4):318-321

7. Kistler W. Synovial chondromatosis of the knee joint: a rarity during childhood. Eur J Pediatr Surg. $1991 ; 1(4): 237-239$.

8. Shearer H, Stern P, Brubacher A, Pringle T. A case report of bilateral synovial chondromatosis of the ankle. Chiropr Osteopat. 2007; 24:18.

9. Yu GV, Zema RL, Johnson RW. Synovial osteochondromatosis. A case report and review of the literature. J Am Podiatr Med Assoc. 2002;92(4):247-254.

10. Pai VR, van Holsbeeck M. Synovial osteochondromatosis of the hip: role of sonography. J Clin Ultrasound. 1995;23(3):199-203.

11. Ginaldi S. Computed tomography feature of synovial osteochondromatosis. Skeletal Radiol. 1980;5(4):219-222.

12. Hsueh CJ, Huang GS, Juan CJ, Wang SG, Liou CH, Hsiao HS, Gao HW. Synovial chondroma of the ankle in a young child after recent trauma: $C T$ and MR features. Clin Imaging. 2001 ;25(4):296-299.

13. Tibrewal SB, lossifidis A. Extra-articular synovial chondromatosis of the ankle. J Bone Joint Surg Br. $1995 ; 77(4): 659-660$.

14. Davis RI, Hamilton A, Biggart JD. Primary synovial chondromatosis: a clinicopathologic review and assessment of malignant potential. Hum Pathol. 1998;29(7):683-688. 